\title{
FLUORESCENT IN SITU HYBRIDIZATION AND FLOW CYTOMETRY AS TOOLS TO EVALUATE THE TREATMENTS FOR THE CONTROL OF SLIME-FORMING ENTEROBACTERIA IN PAPER MILLS
}

C. Esperanza Torres ${ }^{1}$, Alicia Gibello ${ }^{2}$, Mar Nande $^{3}$, Margarita Martin ${ }^{3}$ and Angeles Blanco ${ }^{1 *}$

${ }^{1}$ Chemical Engineering Department. Faculty of Chemistry.

${ }^{2}$ Microbiology (Animal Health) and ${ }^{3}$ Biochemistry and Molecular Biology IV Department. Faculty of Veterinary.

Complutense University of Madrid. Madrid 28040. Spain

Running title, Control of slime-forming enterobacteria using fluorescent in situ hybridization and flow cytometry.

${ }^{*}$ Corresponding author/Mailing address,

Angeles Blanco

Chemical Engineering Department.

Faculty of Chemistry. Universidad Complutense

Av. Complutense s/n. Madrid 28040

Spain

Tel, +34913944247

Fax, +34913944243

e-mail, ablanco@quim.ucm.es 


\section{Abstract}

Slime formation is a serious problem nowadays in the paper industry. Some enterobacteria are associated with the formation of slime deposits in paper and board mills. Detection and characterization of slime forming bacteria, belonging to the genus Enterobacter, Raoultella and Klebsiella have been achieved by fluorescence in situ hybridization (FISH), using one probe based on the Enterobacterial Repetitive Intergenic Consensus sequence and other two rRNA targeted oligonucleotide probes. The effects of three kinds of antimicrobiological products (biocides, dispersants and enzymes) on these enterobacterial cells were analysed by flow cytometry (FC). Biocides Butrol 1009 and 1072 were the most effective microbiocides against all enterobacterial cells analysed, reaching $90 \%$ of dead bacteria after 24 hours. However, the enzymatic treatment (Buzyme) was not equally efficient on enterobacteria and its microbice capacity varied depending on the type of microorganism. FISH and FC were effective tools to detect important slime forming enterobacteria and to select specific treatments to control microbial problems in the paper industry. 


\section{Introduction}

The lower quality of the recycled fibres, used as raw material in the paper industry today, together with the current operational process trends, such as closed water loops, high temperatures (up to $50{ }^{\circ} \mathrm{C}$ ) and neutral $\mathrm{pH}$, provide favourable environmental conditions for the microbial growth of bacteria, yeasts and fungi (Blanco et al., 1996; Blanco, 2003). One of the problems associated with microbial activity in paper and board mills is the formation of biofilms or slime deposits that affect the paper making process, as well as the quality of the final product. Slime is defined as the accumulation of microbial cells immobilised and embedded in an organic polymer matrix of microbial origin (exopolysaccharides), mixed with fibres, fines, fillers and other organic and inorganic materials from microbial metabolism (Blanco et al., 1996; Blanco, 2003; Rättö et al., 2006).

Problems associated with the slime formation include defects in the final product, like spots and holes, bad odours and loss of optical paper properties; as well as higher productivity losses due to breaks, corrosion, cleaning downtime and chemicals (Sanborn 1944; Blanco et al., 1996; Blanco, 2003, Lahtinen et al., 2006; Rättö et al., 2006). Traditionally, microorganisms in paper mills are mainly controlled by the use of antimicrobial treatments or biocides. Since the nature of the microorganisms present in paper mill slime depends on both the original microbial contamination and the subsequent growth conditions, the treatment efficiency varies widely from mill to mill (Blanco et al., 1996; Blanco, 2003). Nowadays, the restrictions in the use of biocides and the demand of environmentally friendly chemicals ("green biocides") have changed the control treatments towards enzymatic treatments, dispersants or/and specific biocides treatments that affect the predominant microorganisms (Blanco, 2003). Therefore, only the most detrimental microorganisms present in paper mills should be targeted and controlled and this requires the knowledge of the bacterial microbiota present at the mill. 
Investigations into the slime-forming bacteria (SFB) of pulp, paper and board mills showed that the primary slime producers worldwide were members of Enterobacteriaceae with Enterobacter cloacae, Enterobacter aerogenes, Pantoea agglomerans, Klebsiella pneumoniae and Raoultella spp., as the most frequently species isolated (Sanborn, 1944; Neilson \& Sparell, 1976; Väisänen et al., 1998; Blanco, 2003; Gauthier et al., 2000; Gauhier \& Archibald, 2001; Beuchamp et al., 2006; Rättö et al., 2006).

The classic methods of bacterial detection and identification used in industrial processes are timeconsuming and labour-intensive. However, fluorescence in situ hybridization (FISH) is one of the most powerful tools developed in modern microbial ecology for direct specific detection of target microorganisms in their natural environment without the need for cultivation (Amann et al., 1995 and 2001). The drawbacks of conventional FISH method are that its sensitivity is limited by the need for several copies of target DNA and that FISH is unable to determinate the viability of bacteria. To overcome this problem, the standard FISH method has been applied coupled with other methods, FC (Collado \& Sanz, 2007; Fuchs et al, 2000), DNA microarrays and in situ polymerase chain reaction (PCR) (Armisen \& Servais 2004; Bathe \& Hausner, 2006).

The aim of this work was to develop new probes to detect the main enterobacteria in microbial populations present in the paper mills, in order to evaluate the efficiency of different treatments to eliminate them. Bacterial detection and identification have been carried out by a FISH method that includes two new probes targeted to $16 \mathrm{~S}$ rRNA and a probe based on the conserved central region of the Enterobacterial Repetitive Intergenic Consensus (ERIC) sequences, which are located at a high copy number in extragenic regions of the Enterobacteriaceae genome (Bachelier et al., 1999; Hulton et al., 1991; Wilson \& Sharp, 2006). The viability of these enterobacteria after the chemical treatments was measured by FC. This work showed the utility of 
FISH and FC as tools to characterize microbial population and to control the slime-forming enterobacteria in paper mills.

\section{Materials and Methods.}

Microorganisms and culture conditions. The (SFB) used in this study (Bacillus megaterium E022115, Enterobacter cloacae E-022114 and E-022119, Enterobacter aerogenes Bac, Raoultella planticola E-022116 and Klebsiella pneumoniae E-11927) were isolated from slime samples collected from two Finnish and one Spanish paper mill (Rätö et al., 2006). The identification of these isolates was carried out by biochemical characterization, using API systems (BioMérieux SA), ribotyping and partial 16S rDNA sequencing (around 450 nucleotides), as described previously (Rätö et al., 2006).

Type and reference strains were obtained from the Spanish Type Culture Collection. The following bacteria were used for the specificity studies of FISH- probes: Aeromonas caviae CECT 838, Yersinia ruckeri CECT 955, Serratia marcescens CECT 846, Pantoea agglomerans CECT 850, Kluyvera ascorbata CECT 861, Escherichia coli CECT 434, Proteus mirabilis CECT 172, Burkholderia cepacia CECT 322, Pseudomonas fluorescens CG5 (Garbi et al., 2006), and Klebsiella pneumoniae M5a1. Klebsiella oxytoca DSZ-2 was isolated from a soil and identified by $16 \mathrm{~S}$ rRNA gene sequence analysis.

Each SFB was transferred to the suitable liquid media in order to grow the culture under optimum conditions. To store the strains, several loopfuls of cells were inoculated into small vials containing $15 \%$ glycerol in trypticase soy broth. The vials were stored in a freezer at $-20^{\circ} \mathrm{C}$ until use.

Sampling and processing of slime samples. Nine slime samples were collected from the wet end of a board paper machine using 100\% recovered paper as raw material. The mill uses mixed 
recovered paper of low quality and has a totally closed water system, with a specific water consumption of $1.5 \mathrm{~m}^{3} / \mathrm{t}$ of paper. The deposits were collected with a sterile spoon from the surface of the forming wire. The deposits were put on a pre-sterilized strainer and flushed with suitable volume of physiological sterile saline. The sample was then transferred to a pre-sterilized tube. Enough air space was left in the container to avoid anaerobic conditions before closing tightly. The slime was processed no later than two hours after it was collected at the mill.

On the other hand, slime deposits were grown under aerobic conditions on polypropylene coupons in a continuous-flow circuit of $10 \mathrm{~L}$ in the laboratory, by using process water from the board mill as inoculum and under similar conditions than in the mill $\left(\mathrm{pH}\right.$ of $\left.7,30^{\circ} \mathrm{C}\right)$. The continuous-flow circuit consists of two independently modified Pedersen systems (Pedersen, 1982). Each system is composed of two boxes containing 10 coupons in each box. Nine slime samples were collected after three days. The boxes were opened from the top and the coupons were removed with a sterile pincer. The formed biofilm was transferred to a pre-steriliser container and washed three times with PBS (buffer solution $\mathrm{pH} 7$ ) containing 0.05\% Tween 20. The samples were then processed for FISH analysis by using the cell fixation protocol described below.

Fluorescence in situ hybridization analyses. (i) Oligonucleotide probe design. The KPN-1 and ENT-1 probes were designed from the retrieved sequences from genes encoding 16S rRNA and their specificities were analyzed with the Nacional Center for Biotechnology Information Blast search program (http,/www.ncbi.nlm.nih.gov/). The probe KPN-1 (5'AAGGCGTTAAGGTTAATAA-3') was designed mainly for targeting the 16S rDNA of Klebsiella and Raoultella species. This probe was designed from positions 434-452 of DNA codifing 16S-RNA from $K$. pneumoniae and $R$. planticola respectively (accession numbers AF130982 and AF129443). The probe ENT-1 (5'-CAGCAATTGACGTTACC-3'), which 
targeted the 16S rDNA of Enterobacter sp. and Pantoea agglomerans (AF157688), was designed from positions $442-458$ of DNA codifing 16S rRNA from E. cloacae (accession numbers AJ251469). The accessibility of these probes to the 16S rRNA molecule by FISH was also checked according to the ARB software (http,//www.arb-home.de; Kumar et al., 2005). The ERIC-1 probe used in this work (5'-ATGTAAGCTCCTGGGGATTCAC-3') targets from 42 to 63 bp position of ERIC consensus sequence present in all Enterobacteriaceae (Bachelier et al., 1999; Hulton et al., 1991; Wilson \& Sharp, 2006). These probes were covalently labelled at their 5'end with the isothiocyanate derivative (CY3) or with fluorescein isothiocyanate (FITC), and purified by reverse-phase liquid chromatography.

The previously published Kpn probe (5'-CCTACACACCAGCGTGCC-3'), specific for $K$. pneumoniae (Kempf et al., 2000), targets 23S RNA of this bacterium. Probe EUB_338 (GCTGCCTCCCGTAGGAGT), complimentary to a region of the 16S rRNA specific for the domain bacteria, was used as a positive control to test the efficiency of hybridization (Amann et al., 1995). Probes were synthesized by Transgenomic (UK). Alternatively, the samples were stained with DAPI (4', 6'-diamino-2-phenylindole) which detects DNA of bacteria and other microorganisms.

(ii) Probe check and optimisation of stringency. The hybridisation efficiency of labelled oligonucleotide probes was estimated by monitoring the fluorescence intensity of pure cultures of target and closely related non-target organisms. Whole cell hybridisation was performed at different temperatures with increasing concentrations of formamide (from 0 to $50 \% \mathrm{v} / \mathrm{v}$, in steps of $10 \%$ ) to determine conditions for the discrimination of target and non-target organisms for each probe. The species and group specific probes were applied simultaneously with probe EUB338. In the case of the probes Kpn and EUB338, FISH assays were carried out as described 
by other authors (Amann et al., 1995; Kempf et al., 2000; Peters et al., 2006). Hybridization times varied from $2 \mathrm{~h}$ for the probe Eub338, to $16 \mathrm{~h}$ for the specific probes.

(iii) In situ hybridisation on membrane filters. Cells growing in the logarithmic phase were harvested by centrifugation and resuspended in $0.5 \mathrm{ml}$ of PBS with $30 \mu \mathrm{l}$ of cell suspensions, adjusted to get $10^{5}-10^{7}$ cells $\mathrm{cm}^{-2}$. They were placed on polycarbonate filters $(47 \mathrm{~mm}$ diameter, $0.2 \mu \mathrm{m}$ pore size; Isopore GTTP, Millipore, Germany) and filtered by using a glass tower. Cells were permeabilised with different lysozyme concentrations (Sigma lysozyme in buffer containing $100 \mathrm{mM}$ tris- $\mathrm{HCl}, 50 \mathrm{mM}$ EDTA $\mathrm{pH}$ 8). Incubation temperature and time were tested in order to optimise cell permeabilisation. Cells were washed twice with $2 \mathrm{ml}$ of PBS and dehydrated by using an ethanol series of 70, 90 and $96 \%(\mathrm{v} / \mathrm{v})$ for 10 min each at room temperature.

Air-dried filters were ready for hybridization and could be stored at $-20^{\circ} \mathrm{C}$ for several weeks without apparent change. Each filter was cut into eight sections that were placed on glass slides. Each section from the same filter can be used with different probes or with a combination of probes. Filters were heated in a $2 \mathrm{XSSC}$ formamide solution $(70 \%$ Formamide, $0.3 \mathrm{M} \mathrm{NaCl}$, and $0.03 \mathrm{M} \mathrm{NaCitrate,} \mathrm{pH} \mathrm{7)}$ at $70^{\circ} \mathrm{C}$ for $2 \mathrm{~min}$. Filter sections were covered with $50 \mu \mathrm{l}$ of hybridisation buffer $(0.9 \mathrm{M} \mathrm{NaCl}$, and $20 \mathrm{mM} \mathrm{HCl}$-Tris, $\mathrm{pH} 7)$, and the fluorescent probes were added at a final concentration of $8 \mathrm{ng} \mu \mathrm{l}^{-1}$. Then the filters were incubated at the appropriate temperature in an equilibrated chamber. After $12 \mathrm{~h}$ incubation, the filters were transferred to a prewarmed vial containing $50 \mathrm{ml}$ of washing buffer $(0.9 \mathrm{M} \mathrm{NaCl}, 0.05 \%$ SDS and $20 \mathrm{mM} \mathrm{HCl}-$ Tris, $\mathrm{pH}$ 7) and incubated without shaking for $20 \mathrm{~min}$. The filters were rinsed with distilled water, air-dried, and mounted in a Vectashield Mounting Medium. Each experiment was repeated three times and, in each repetition, hybridizations were performed with at least three replicates. Negative controls were also prepared for each test sample. These controls were applied to assess potential non-specific binding, i.e., the designed probes were used with non target reference bacteria. Autofluorescence of cells was also determined with the negative controls.

Laser Confocal Microscopy and analysis. Fluorescent probes were detected and imaged using a MRC-1024 confocal microscope (Bio-Rad, Hempel Hempstead, UK). FITC label probe was 
excited using a $488 \mathrm{~nm}$ emitting Ar laser, and the fluorescence recovered through 515/30 BP filter. CY3-tagged probe was excited using a $550 \mathrm{~nm}$ emiting laser, and fluorescence was recovered using a 600/30 BP filter. When FITC- and CY3-tagged probes were used in the same sample, sequential acquisition was used to obtain the images. Lasersharp and Laserpix softwares (Bio-Rad) were used to analyse the images.

Slime control treatments. The effect on Enterobacterial cellular viability of six slime control treatments with different modes of action were analysed: four biocides (Butrol 881, Butrol 1009, Butrol 1072, Butrol 1130) one dispersant (Busperse 235) and one commercial enzyme preparation (Buzyme). All chemicals are commercial products supplied by Buckman laboratories (Belgium). The chemistry and the mode of action of each product are given in Table 1. Pure cultures of selected bacteria were incubated in $250 \mathrm{ml}$ of peptone saline medium and incubated overnight at $37^{\circ} \mathrm{C}$ in a lab shaker. Then, $100 \mathrm{ml}$ aliquot of each incubated culture was mixed with the studied slime-acting product. The effects of $100 \mathrm{ppm}$ of these chemicals were analyzed at different times $(0 \mathrm{~h}, 2 \mathrm{~h}, 8 \mathrm{~h}$ and $24 \mathrm{~h})$ by $\mathrm{FC}$.

Cell viability analyses by FC. In order to obtain information about cellular viability, propidium iodide (PI) (from Sigma) was selected as the dye exclusion marker and was combined with SYTO13 (from Molecular Probes) as a survival DNA stain. Both stains were simultaneously added at concentrations of $0.1 \mu \mathrm{g} / \mathrm{ml}$ PI and $2.5 \mu \mathrm{L}$ of SYTO13 to $1 \mathrm{ml}$ of sample and incubated during 10 minutes at $37^{\circ} \mathrm{C}$ for staining. The samples were finally analysed by $\mathrm{FC}$. We used a Becton Dickinson FACScalibur cytometer with a laser emitting at $488 \mathrm{~nm}$. Samples were run at low speed and data were acquired in log mode and around 10.000 events were taken (Gasol et al., 1999). Cells with damaged membranes were penetrated by both the dead stain (PI), and the live stain (SYTO13). When the six antimicrobiological products were assayed on pure cultures of $E$. aerogenes Bac, E. cloacae E-022114 and K. pneumoniae E-011927, the analysis by FC was 
performed by making a comparison plot between the size of the population and the complexity of the sample, and between the IP and the SYTO13 fluorescence in order to quantify the cellular viability. On the basis of different plots, it was possible to differentiate a population of bacteria and to distinguish the percentages of lived and dead cells of each experiment. The percentage of cellular viability was performed adding the superior quadrants of dotplot IP fluorescence versus and SYTO13 fluorescence.

\section{Results}

Optimization of hybridization conditions. Optimal FISH conditions were analyzed on the selected SFB strains, Enterobacter cloacae strain E-022114 and 022119, Enterobacter aerogenes Bac, Raoultella planticola E-022116 and Klebsiella pneumoniae E-11927. In order to enhance the FISH hybridization sensitivity (i.e., the percentage of hybridized cells in the DAPI stained cells) of analyzed SFB, the effect of temperature and different permeabilizers was evaluated, i.e., formamide and lysozyme (Table 2). Samples that were not treated with lysozyme showed lower fluorescence signal intensity and FISH hybridization efficiency. In terms of FISH hybridization efficiency (with Eub338 and specific probes), the results showed an increase from $(48 \pm 3) \%$ in the unpermeabilised samples to $(92 \pm 5) \%$ after 60 min of permeabilisation. We could not detect significant cell loss, comparing DAPI and FISH with Eub338 probe counts, in samples after 60 min of lysozyme treatment. The highest FISH hybridization efficiency, for each strain and probe observed when cell cultures were harvested at the exponential growth phase under optimal hybridisation temperatures are shown in Table 2.

Probe specificity. The specificity of the oligonucleotide probes ERIC-1, KPN-1 and ENT-1 for targeted SFB was evaluated by performing FISH assays, with pure cultures of bacterial SFB 
isolates and reference strains (see Microorganisms and culture conditions), under the conditions described in Table 2.

Cell counts obtained for each SFB strain of the performed experiments are shown in Table 3. The results obtained with ERIC-1 showed that the five SFB bacterial strains were successfully labelled with this probe, specific for the Enterobacteriaceae group. In fact, only the enterobacterial strains were labelled with ERIC-1 probe. The highest FISH efficiency between the SFB was observed with $K$. pneumoniae E-11927 (92 $\pm 1.2 \%)$, and the lowest with the E. aerogenes strain $\mathrm{Bac}(82 \pm 1.4 \%)$. Reference strains and bacteria different from the Enterobacteriaceae group were not labelled with the ERIC-1 probe.

Satisfactory results were also obtained when the probe KPN-1 was used in the FISH experiments to detect the bacteria of Klebsiella and Raoultella genera. K. pneumoniae E-11927, K. oxytoca DSZ-2 and R. planticola E-022116 strains showed, a high fluorescence signal intensity consistent with a high hybridization efficiency (Table 3). However, fluorescence with this probe was also observed with E. aerogenes Bac. Besides this, the specificity of the probe KPN-1 was established with the results obtained with the other enterobacteria tested, and neither of these other strains were labelled with KPN-1 in the FISH experiments.

A probe specific for Enterobacter sp. and Pantoea agglomerans could not be designed on the basis of 16S rRNA sequences. In fact, probe ENT-1 is complementary to Salmonella enterica, and also to Citrobacter koseri, as revealed by a BLAST search. Either Enterobacter strains or P. agglomerans CECT 850 (Table 3) could be labelled with this probe. The results obtained for the SFB isolates showed that the highest FISH efficiency was obtained with E. cloacae E-022114 and E-022119, although a lower hybridization sensitivity $(86 \pm 0.4) \%$ was detected with E. aerogenes Bac (Table 3). Neither R. planticola E-022116 nor K. pneumoniae E-11927 were labelled with ENT-1, and neither of the other enterobacterial strains analyzed was labelled with 
this probe. Finally, the genus-specific Kpn probe only hybridized with K. pneumoniae E-11927 and K. oxytoca DSZ, (data not shown), according to its specificity described by Kempf et al. in 2000.

FISH analysis with ERIC-1, KPN-1, Kpn and ENT-1 probes on bacterial population of slime biofilm samples revealed homogeneus data with an average of $45 \%$ of enterobacteria of the total microorganisms involved in the slime formation (Figure 1, Table 4). The specificity of the groupspecific probes also showed that bacteria compatible with the Klebsiella/Raoultella group and with Enterobacter spp. or Pantoea agglomerans were present in these samples (Table 4). The existence of these bacteria groups in these samples was also confirmed by their isolation, on culture medium plates, and further characterization as described by Rättö et al in 2006.

Analysis of bactericidal treatments. The analysis by FC of the bactericidal effect of the six antimicrobiological products on pure cultures of E. aerogenes Bac, E. cloacae E-022114 and K. pneumoniae E-011927 showed that not all slime control chemicals are equally efficient. The main results are summarized in Figure 2, where it has been shown that biocides Butrol 1009 (B4) and 1072 (B3) were highly effective for all strains. However, the treatment with Butrol 881(B2) was only effective on E. cloacae and Butrol 1130 (B1) was not effective at the studied dosage in any of the strains under study. It was also observed that the effect of the dispersant depends on the studied species. Then, Busperse (B5) was moderately effective on E. cloacae and K. pneumoniae at short times $(2 \mathrm{~h}$ ) but very efficient after $24 \mathrm{~h}$ (yielding $>80 \%$ and $95 \%$ of dead cells respectively), while it was not efficient on E. aerogenes (Figure 2A). Likewise, the enzymatic treatment with Buzyme (B6) was very effective on K. pneumoniae ( $>90 \%$ of dead cells), moderately effective on E. cloacae ( $>85 \%$ of dead cells) and was very limited on E. aerogenes ( $60 \%$ of dead cells). Because enzymatic treatments are a "friendly" alternative to control the microbial activity due to their non-toxic character and their biological origin, Buzyme 
was chosen for use at double dosage on one biofilm sample (biofilm 9), which contained significative amounts of Klebsiella cells (Table 4). After the Buzyme treatment of biofilm 9, enterobacteria was reduced to $15 \%$ and cells belonging to the genus Klebsiella were almost not detectable by FISH. Moreover, because none of treated enterobacterial cells were labelled with probe ENT-1, it seems that a bacteria belonging to the Enterobacter/Pantoea group, sensitive to Buzyme, was present in this biofilm sample. These results showed the effectiveness of the enzymatic treatment on this sample, as well as the usefullness of FISH to choose the most adequate of the biocide treatments.

\section{Discussion}

Microbial growth and slime formation in the paper mill environment produces a wide range of operational problems for the papermaker, slime detachment, microbiologically induced corrosion, odour problems, etc. (Sanborn, 1944; Blanco et al., 1996; Blanco 2003). An increasing awareness of the detrimental effects of biofilm formation has led to the requirement for in situ sampling that can facilitate further examination of the microbial components of the biofilm. This is particularly important not only for normal monitoring purposes, but also to evaluate the effectiveness of biocide treatments. FISH and FC applied in papermaking could be used to reach these objectives, since these methods have already been used to typify the microbial composition of environmental and clinical samples (Fuchs et al., 2000; Kempf et al., 2000; Collado \& Sanz, 2006, Peters et al., 2006).

Recent studies on characterization of the bacterial community in paper mill-derived biofilms revealed that enterobacteria belonging to the Enterobacter, Pantoea, Klebsiella and Raoultella genera are usually found forming slimes that increase rapidly and abundantly (Sanborn, 1944; Gauthier et al., 2000; Gauhier \& Archibald, 2001; Beuchamp et al., 2006; Rättö et al., 2006). As 
well as other taxon-rich families, members of the Enterobacteriaceae have been subject of extensive analysis of 16S rDNA and taxonomic changes (Spröer et al., 1999; Drancourt et al., 2001). Based on comparative $16 \mathrm{~S}$ rDNA sequence analysis, it is clear that there is a high degree of relatedness ( $98 \%$ of sequence similarity) between different genera of enterobacteria (Dauga, 2002), and the design of specific probes is very difficult. In fact, the recent FISH studies for bacterial detection used probes for genus or species cluster (Peters et al., 2006). Both ENT-1 and KPN-1 probes were designed to dominantly target to $16 \mathrm{~S}$ rRNA from each genera-group, under optimized conditions. The access of rRNA-targeted oligonucleotide probes to their target site may be hindered by the three-dimensional structure of the ribosome (Kumar et al., 2005; Yilmaz et al., 2006). The high sensibility showed by these probes could be also attributed to the accessibility of rRNA structure to the probe, since they were designed by the ARB software taken in account their accessibility to their molecule target (Kumar et al., 2005; Yilmaz et al., 2006). Hybridizations performed with the probe KPN-1 revealed the utility of this probe to detect bacteria belonging to the Klebsiella/Raoultella group, although fluorescence was also observed for E. aerogenes Bac. However, the cross-hybridization obtained with the KPN-1 probe for E. aerogenes is not surprising if considering the close relation between these two species based on $16 \mathrm{~S}$ rDNA sequence data. In fact, molecular phylogeny based on 16S rDNA and also on groE and gyrB sequences proposed to transfer E. aerogenes to the Klebsiella genus (Dauga, 2002). FISH assays carried out with probe ENT-1 showed good results in order to detect Enterobacter/Pantoea SFB bacteria. This probe showed a lower specificity by silico analysis, because this probe could also target homologous positions in Citrobacter koseri and Salmonella spp. Although Citrobacter sp. and Salmonella sp. species have not been checked in this study, the possibility of this probe would detect these genera is not a handicap considering that Citrobacter freundii have been occasionally recovered as primary slime producer bacteria 
(Gauthier \& Archibald, 2001; Beuchamp et al., 2006; Rättö et al, 2006). Otherwise, Salmonella cells have been never found in paper mills (Gauthier \& Archibald, 2001). The combined use of probes Kpn and KPN-1, with a broader specificity, allowed distinction of the Klebsiella SFB strains from those belonging to Raoultella genera. Likewise, the simultaneous application of probes ENT-1 and KPN-1 proved to be a suitable tool for the identification of E. aerogenes.

This is the first time that a probe based on high repetitive ERIC sequence has been used in FISH experiments. FISH analysis with ERIC-1 probe on bacterial population of slime biofilm samples revealed that enterobacteria were present as a high proportion of total microorganisms (about $45 \%$ of the total DAPI-stained eubacteria). This result is in agreement with data previously reported in other paper mills (Sanborn, 1944; Beucham et al, 2006) and where Klebsiella spp. and Enterobacter spp. represented the predominant coliform populations in all primary SFB (Sanborn, 1944; Gauthier et al., 2000; Gauthier and Archibald, 2001; Rättö et al., 2006). When FISH was applied on biofilm samples, enterobacteria belonging to genera Klebsiella and Enterobacter were also found in a significant amount (Table 4).

Microbial control of SFB usually employed a mixture of products without the analysis of microbial composition. In this work six kinds of antimicrobiological treatments, with different modes of action, were analyzed on Klebsiella sp. and Enterobacter sp. strains isolated from a paper mill. As it has been shown in Figure 2, not all slime control chemicals are equally efficient. It is observed for example, that the effect of the dispersant and enzymatic treatment (buzyme) depends on the studied species (Figure 2). Butrol 1009 and 1072 bacterial treatment were the most effective microbiocide against all enterobacterial cells analysed, while Butrol 1130 was not efficient and Butrol 881 was only efficient on E. cloacae after $24 \mathrm{~h}$.

Enzymatic treatments are interesting control slime treatments from an environmental point of view. Although enzymatic treatment (Buzyme) was less effective than some chemicals (Figure 
2), its microbice capacity on K. pneumoniae and E. cloacae, yielding more than $75 \%$ of dead bacteria after $2 \mathrm{~h}$ and more than $90 \%$ of dead cells after $24 \mathrm{~h}$, makes it an interesting environmentally alternative (Figure 2). In this sense, results after the enzymatic treatment of one biofilm slime samples (biofilm 9), showed that bacteria belonging to these genera were almost not detected by FISH and enterobacteria were reduced to $15 \%$ (Table 4).

In summary, the availability of FISH methods for the paper industry will allow papermakers a more responsible use of biocides, by treating only the most problematic strains and then selection of the most adequate treatment, according to the microorganisms present in the process, without expensive mill trials.

\section{ACKNOWLEDGMENTS.}

We would like to acknowledge the financial support of the EU to the projects Novozymes (GRDI-2000-25676) and Odour Control (016730-FP6-2003-SME-1) and of the Community of Madrid to the project PROLIPAPEL (S-0505/AMB0100). We also thank Yadhu Kumar (Universität München, Germany) for his help in the probe analysis with the ARB software and Buckman Laboratories for their products. 


\section{References,}

Amann RI, Fuchs BM, Behrens, S (2001) The identification of microorganisms by fluorescence in situ hybridisation. Curr Opin Biotechnol 12: 231-236

Amann RI, Ludwig W, Schleifer KH (1995) Phylogenetic identification and in situ detection of individual microbial cells without cultivation. Microbiol Rev 59: 143-169

Armisen TG, Servais P (2004) Combining direct viable count (DVC) and fluorescent in situ hybridisation (FISH) to enumerate viable E. coli in rivers and wastewaters. Water Sci Technol 50:271-5

Bachelier S, Clément JM, Hofnung M (1999) Short palindromic repetitive DNA elements in enterobacteria: a survey. Res Microbiol 150: 627-639

Bathe S, Hausner M (2006) Design and evaluation of 16S rRNA sequence based oligonucleotide probes for the detection and quantification of Comamonas testosteroni in mixed microbial communities. BMC Microbiol 6:54

Beauchamp CJ,Simao-Beaunoir AM, Beaulieu C, Chalifour FP (2006) Confirmation of E. coli among other thermotolerant coliform bacteria in paper mill effluents, wood chips screening rejects and paper sludges. Water Res 40: 2452-2462

Blanco A (2003) Microbiology in papermaking. Recent Res Devel Appl Microbiol Biotechnol 1: 87-134

Blanco A, Negro C, Gaspar I, Tijero J. (1996) Slime problems in the paper and board industry. Appl Microbiol Biotechnol 46: 203-208

Collado MC, Sanz Y (2007) Quantification of mucosa-adhered microbiota of lambs and calves by the use of culture methods and fluorescent in situ hybridization coupled with flow cytometry techniques. Vet Microbiol 121: 299-306 
Dauga C (2002) Evolution of the gyrB gene and the molecular phylogeny of Enterobacteriaceae: a model molecule for molecular systematic studies. Int J Syst Evol Microbiol 52: 531-47

Drancourt M, Bollet C, Carta A, and Rousselier P. (2001) Phylogenetic analyses of Klebsiella species delineate Klebsiella and Raoultella gen. nov., with description of Raoultella ornithinolytica comb. nov., Raoultella terrigena comb. nov. and Raoultella planticola comb. nov. Int J Syst Evol Microbiol 51: 925-32

Fuchs BM, Zubkov MV, Sahm K, Burkill PH, Amann R (2000) Changes in community composition during dilution cultures of marine bacterioplankton as assessed by flow cytometric and molecular biological techniques. Environ Microbiol 2: 191-201

Garbi C, Casasus L, Martinez-Alvarez, R, Robla JI, Martín M (2006). Biodegradation of oxadiazon by a soil isolated Pseudomonas fluorescens strain CG5: Implementation in an herbicide removal reactor and modelling. Water Res 40: 1217-1223

Gasol JM, Zweifel UL, Peters F, Fuhrman JA, Hagström A (1999) Significance of size and nucleic acid content heterogeneity as measured by flow cytometry in natural planktonic bacteria. Appl Environ Microbiol 65: 4475-4483

Gauthier F, Archibald F (2001) The ecology of "fecal indicator" bacteria commonly found in pulp and paper mill water systems. Water Res 35: 2207-2218

Gauthier F, Neufeld JD, Driscoll BT, Archibald F (2000) Coliform bacteria and nitrogen fixation in pulp and paper mill effluent treatment systems. Appl Environ Microbiol 66: 5155 5160

Hulton CSJ, Higgins CF, Sharp PM (1991) ERIC sequences: a novel family of repetitive elements in the genomes of Escherichia coli, Salmonella typhimurium, and other enterobacteria. Mol Microbiol 5: 825-834 
Kempf VAJ, Trebesius K, Autenrieth IB (2000) Fluorescent in situ Hybridization allows rapid identification of microorganisms in blood cultures. J Clin Microbiol 38: 830-838

Kumar Y, Westram R, Behrens S, Fuchs B, Glöckner FO, Amann R, Meier H, Ludwig W (2005) Graphical representation of ribosomal RNA probe accessibility data using ARB software package. BMC Bioinformatics 6: 61

Lahtinen T, Kosone M, Tiirola M, Vuento M, Oker-Blom C (2006) Diversity bacteria contaminating paper machines. J Ind Microbiol Biotechnol 33: 734-740

Neilson AH, Sparell L (1976) Acetylene Reduction (Nitrogen Fixation) by Enterobacteriaceae Isolated from Paper Mill Process Waters. Appl Environ Microbiol 32: $197-205$

Perdersen K. (1982) Method for studing microbial biofilms in flowing-water systems. Appl Environ Microbiol 43: 6-13

Peters RPH, Savelkoul PHM, Simoons-Smit AM, Danner SA, Vandenbroucke-Grauls, CMJE, van Agtmeael MA (2006) Faster identification of pathogens in positive blood cultures by fluorescence in situ hybridization in routine practice. J Clin Microbiol 44: 119-123

Rättö M, Verhoef R, Suihko M-L, Blanco A, Schols HA Voragen AGJ, Wilting R, Siika-aho M, Buchert J (2006) Colanic acid is an exopolysaccharide common to many enterobacteria isolated from paper-machine slimes. J Ind Microbiol Biotechnol 33: 359-367

Sanborn J.R. (1944). Slime-producing Coliform and Coliform-like Bacteria. J. Bacteriol. 48: 211-217.

Spröer C, Mendrock U, Swiderski J, Lang E, Stackebrandt E (1999) The phylogenetic position of Serratia, Buttiauxella and some other genera of the family Enterobacteriaceae. Int J Syst Bacteriol 4:1433-8 
Väisänen OM, Weber A, Bennasar A, Rainey FA, Busse HJ, Salkinoja-Salonen M (1998). Microbial communities of printing paper machines. J Appl Microbiol 84: 1069-1084

Wilson LA, Sharp PM (2006) Enterobacterial repetitive intergenic consensus (ERIC) sequences in Escherichia coli: evolution and implications for ERIC-PCR. Mol Biol Evol 23: $1156-1168$

Yilmaz L, Ökten HE, Noguera DR (2006) Making all parts of the 16S rRNA of Escherichia coli accessible in situ to single DNA oligonucleotides. Appl Environ Microbiol 72: 733-744 


\section{List of tables}

Table 1, Slime-acting chemicals and enzymes applied on slime-forming bacteria.

\begin{tabular}{|c|c|c|c|c|c|c|}
\hline Treatment & $\begin{array}{l}\text { Butrol } \\
1130\end{array}$ & $\begin{array}{c}\text { Butrol } \\
881\end{array}$ & Butrol 1072 & Butrol 1009 & Buzyme & Busperse \\
\hline Chemistry & BHAP $^{*}$ & Thiocarbonate & $\begin{array}{c}\mathrm{TCMTB}^{* *}+\mathrm{MTC}^{* * *} \\
\text { diluted }\end{array}$ & $\mathrm{TCMTB}^{* *}+\mathrm{MTC}^{* * *}$ & Protease & Dispersant \\
\hline $\begin{array}{l}\text { Mode of } \\
\text { action }\end{array}$ & 2 & 2 & 1,2 & 1,2 & $\begin{array}{r}\text { Preve } \\
\text { adl }\end{array}$ & $\begin{array}{l}\text { ntion of } \\
\text { esion }\end{array}$ \\
\hline
\end{tabular}

BHAP*, Bromohydroxyactophenone $\rightarrow$ effect 2

TCMTB**, Thyocyanomethylbenzothiazole $\rightarrow$ Effect 1 (Complexion of metals).

MTC***, Methylenebisthiocyanate $\rightarrow$ effect 2 (Direct inhibition of metabolism). 
Table 2, Optimisation of whole-cell hybridisation with the designed probes on the slime-forming

\begin{tabular}{|c|c|c|c|c|c|c|c|}
\hline \multirow[t]{2}{*}{ Bacteria } & \multirow[t]{2}{*}{$\begin{array}{c}\text { Lysozyme } \\
\left(\mathrm{mg} \mathrm{ml}^{-1}\right)\end{array}$} & \multicolumn{3}{|c|}{$\begin{array}{c}\text { Formamide } \\
\text { (\%) }\end{array}$} & \multicolumn{3}{|c|}{$\begin{array}{c}\text { Temperatura } \\
\left({ }^{\circ} \mathrm{C}\right)\end{array}$} \\
\hline & & ERIC-1 & KPN-1 & ENT-1 & ERIC1r & KPN-1 & ENT-1 \\
\hline E. cloacae E-022114 & 1.0 & 20 & - & 10 & 57 & - & 37 \\
\hline E. cloacae E-022119 & 1.0 & 0 & - & 10 & 55 & - & 37 \\
\hline E. aerogenes Bac & 0.1 & 20 & 20 & 10 & 57 & 43 & 37 \\
\hline K.pneumoniae E-011927 & 0.1 & 20 & 30 & - & 59 & 40 & - \\
\hline R. planticola E-022116 & 0.1 & 0 & 30 & - & 55 & 40 & - \\
\hline
\end{tabular}


Table 3, Bacterial detection using different probes on membrane filters from pure cultures Strains Fraction (\%) of total cells (by Dapi) detected with probes,

\begin{tabular}{|c|c|c|c|c|}
\hline & EUB 338 & ERIC-1 & KPN-1 & ENT-1 \\
\hline E. cloacae E-022114 & $94 \pm 1.2$ & $91 \pm 0.2$ & N.D* & $94 \pm 0.3$ \\
\hline E. cloacae E-022119 & $92 \pm 0.5$ & $89 \pm 0.6$ & N.D ${ }^{*}$ & $92 \pm 0.2$ \\
\hline E. aerogenes Bac & $89 \pm 1.1$ & $82 \pm 1.4$ & $75 \pm 1.2$ & $86 \pm 0.4$ \\
\hline K. pneumoniae E-011927 & $97 \pm 0.9$ & $92 \pm 1.2$ & $96 \pm 1.5$ & N.D* \\
\hline \multicolumn{5}{|l|}{ R.planticola E-022116 } \\
\hline & & & & N.D* \\
\hline N.D*: almost undetectable. & $94 \pm 1.2$ & $91 \pm 1.1$ & $93 \pm 0.2$ & \\
\hline
\end{tabular}

This table only shows the results obtained for the paper mill slime bacteria but not the results from the specificity studies.

Data sensitivity for P. agglomerans CECT $850(93 \pm 0.8) \%$ with ENT-1 probe, and K. oxytoca DSZ-2. $(97 \pm 0.2) \%$ with KPN-1 probe ) were similar to E.cloacae and K. pneumoniae E011927, respectivelly. 
Table 4, Bacterial detection using different probes in samples from a paper mill.

\begin{tabular}{|c|c|c|c|c|c|}
\hline & \multicolumn{5}{|c|}{ Fraction (\%) of total cells (by DAPI) detected with probes, } \\
\hline & $\underline{\text { Eub338 }}$ & ERIC-1 & $\underline{\mathrm{KPN}-1}$ & $\underline{\mathrm{Kpn}}$ & ENT-1 \\
\hline BIOFILMS & 92-99 & $33-56$ & $11-30$ & - & $10-22$ \\
\hline Biofilm 9 & $92 \pm 0.9$ & $45 \pm 1.2$ & $16 \pm 0.5$ & $14 \pm 0.5$ & $12 \pm 0.4$ \\
\hline $\begin{array}{l}\text { Biofilm } 9 \text { after } \\
\text { Buzyme treatment }\end{array}$ & & $15 \pm 0.3$ & N.D ${ }^{*}$ & N.D ${ }^{*}$ & N.D* \\
\hline
\end{tabular}

N.D*: Almost undetectable. 


\section{List of figures}
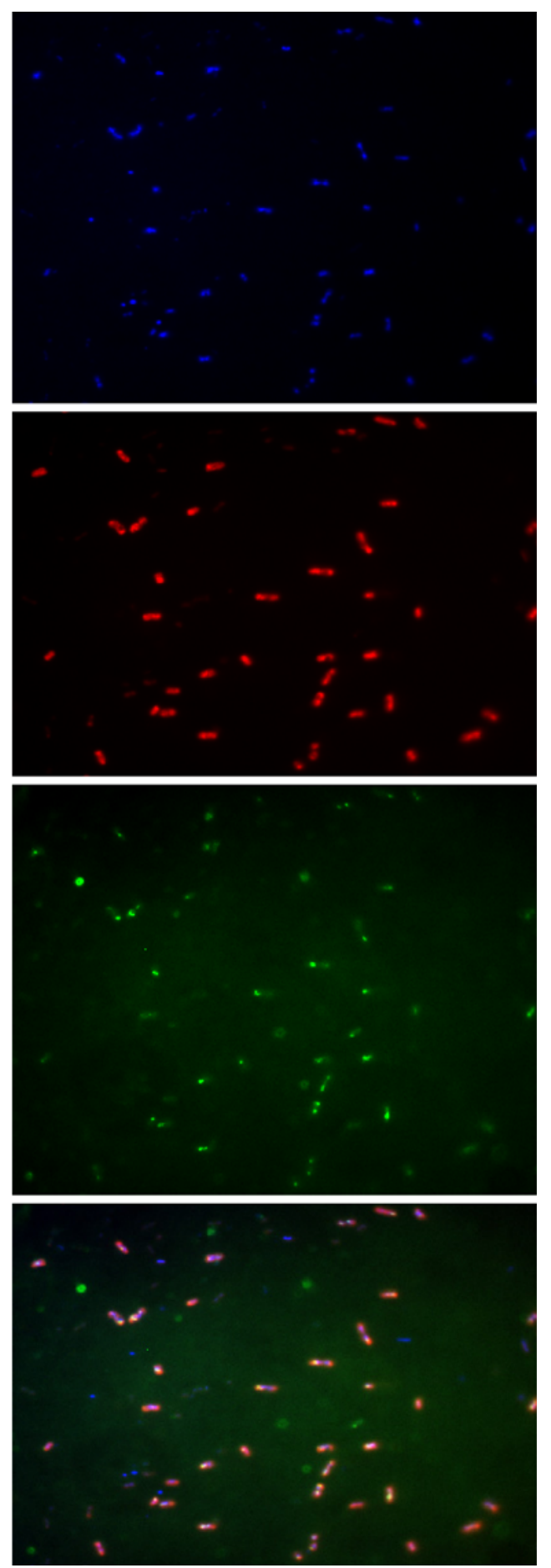

Figure 1, Composite image of the double hybridization of a pure culture of a biofilm sample. Specific detection of ERIC-1 -Positive bacteria with FITC labelled ERIC-1 probe (green), CY3 Labelled EUB 338 (red). DNA stained with DAPI (blue). 

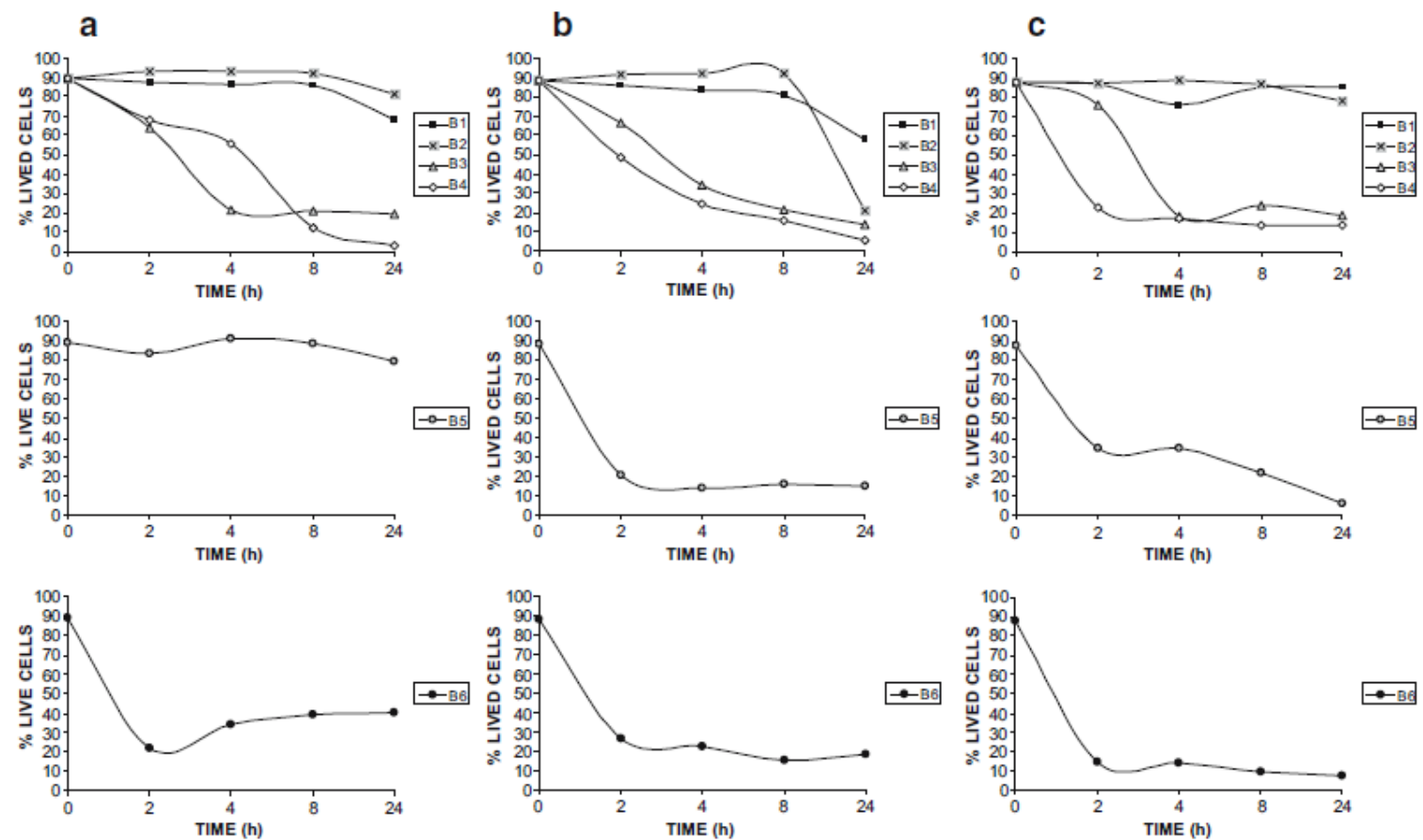

Figure 2, Effect of three kinds of antimicrobiological products on the growth of slimy enterobacterial strains, A) E. aerogenes Bac, B) E. cloacae E-022114 and C) K. pneumoniae E011927. B1, Butrol 1130; B2, Butrol 881; B3, Butrol 1072; B4, Butrol 1009; B5, Busperse 235; B6, Buzyme 2501. 